\title{
Development of prototype machine brake and car safety gear testers for traction lift systems
}

\author{
Albert T P So ${ }^{1}, \mathrm{~K}$ H Lam ${ }^{1}$, Andy C T Kong ${ }^{1}$, Jeff H Tse ${ }^{2}$ \\ ${ }^{1}$ Department of Electrical \& Electronic Engineering, The University of Hong Kong, Hong Kong, People's Republic of China \\ ${ }^{2}$ Electrical \& Mechanical Services Department, the HKSAR Government, Hong Kong, People's Republic of China
}

\begin{abstract}
Machine brakes and safety gears of traction lifts are two critical components of the biggest safety concerns, as the main braking system and redundant fail-safe mechanism respectively stop and hold lift cars from unintended car movement, overspeed or under a free-fall condition during emergency. There are challenges of routine maintenance on how to continually verify the effectiveness of them to mitigate risk potentials of equipment failure. This pilot study intends to design, implement and test low-cost, non-intrusive and on-line prototype testers with the aid of sensors for real-time monitoring of critical parameters of these safety devices. Critical parameters that are measurable include real-time variations of brake lining temperature, brake solenoid current, vibrational patterns of brake arms and lift car, position of lift car, and the actuating status of safety gears. Critical parameters after processing include a newly defined energy of brake arm operation and estimated deceleration rate of a fully loaded car by safety gears operation on an unloaded car. Early signs of abnormalities of these two safety devices can be detected before they fail. Additionally, the prototype testers can facilitate more frequent unloaded full-speed testing of safety gears to verify the effectiveness. The proof-of-concept prototype could be a quick monitoring alternative to existing and new traction lift systems.
\end{abstract}

KEYWORDS Machine brake; car safety gear; tester; lift; vibration; sensor

CONTACT Albert T P So alberttpso@gmail.com

Received 28 October 2020

\section{Introduction}

It is inevitable that many cities face a common problem of aging building services assets over an everincreasing number of buildings. Lift systems, with a general lifespan of over 20 years, are considered a critical one. Maintenance professionals play a key role in ensuring safe operations of lifts. Traditional machine brakes and safety gears in traction lifts are two critical components of biggest safety concerns, serving as redundant fail-safe mechanisms respectively to stop and hold lift cars from unintended car movement, overspeed or in free-fall condition in emergency.

There are about 66,000 lifts of various types in Hong Kong. Over $80 \%$ of which are aged (around 52,800 in number), pending for modernisation or replacement progressively in meeting the latest safetydevice requirements, such as double brake, ascending car overspeed protection, and unintended car movement protection means. Among these aged lifts, around 30\% of them have been operating for over 30 years and some even up to 50 years. The occurrence of serious and fatal accidents serves as cautious reminders for imperative needs for ensuring the reliability of machine brakes and safety gears under emergency situations in particular. There are challenges of routine maintenance on how to continually verify the effectiveness of braking performance against overspeed and safety-gear decelerating performance in a free-fall situation, aiming to mitigate risk potentials of equipment failures.
On machine brake, the main reasons for failure include insufficient brake torque, jamming of the brake mechanism, electrical adhesion of the relay contact, and low balance coefficient (Peng et al., 2018). The spring-loaded brake plungers in machine brake are the key components to activate the brake arms to stop the brake drum of the lift motor. Badly lubricated plungers could make the braking action sluggish, resulting in unintended car movement or partial brake engagement, which can be reflected by a significant increase in temperature of the brake pads. Furthermore, abnormally protruding screws from the lining of brake pads may scratch marks on the brake drum, thereby reducing the effective braking surface and force of the system significantly (EMSD, 2018). Apart from overhaul work, it may be a challenge during routine maintenance to continually monitor the effectiveness of brake plungers and detect any early symptoms of abnormality. That, together with recommendations from literature (to be detailed in the upcoming paragraph), explain why three parameters, including brake arm dynamics, lining temperature, and brake solenoid current were chosen as three critical parameters to directly monitor the machine brake.

On safety gear, its mechanical grippers are activated by the overspeed governor, which could completely stop the lift car even in free-fall condition such as the breaking of suspension ropes. There are various reasons for overspeed governor failure (EMSD, 2013), which can easily be tested inside the machine room. What is mostly difficult to measure is the deceleration rate of the lift car braked by the safety gears in free-fall condition, because 
it has to be confined without a range by international standards, such as EN81-20. It is common practice all over the world to test the safety gear with weights to simulate a full-load condition. However, by then, the key components of gear jaws and guide rails shall be unavoidably subject to mechanical stress and wear, causing the test to be invasive. In addition, there is a fundamental difference between the statutory/standard requirements and the practical tests in a full loaded free-fall testing scenario because the suspension ropes are still intact during practical tests, unavoidably enabling the lift car to decelerate due to the existence of its counterweight (Tim, 2014). Therefore, the fourth critical parameter is the measurement of the deceleration rate monitored by vibrational patterns in truly free-fall safety gear activation condition.

Over the years, different systems have been developed to monitor the condition of machine brake. Lamb et al. (1993) used an embedded temperature resistive sensor to monitor the real-time temperature and integrity of the brake lining. Hubbard et al. (2002) monitored the lift motor current to determine the proper function of brakes. Emy et al. (2009) used a sensor to detect the movement of a brake magnet armature tappet to monitor the state of brake device and found that the more worn-out the brake lining, the smaller the distance between the armature and the brake magnet housing. Fischer (2008) developed a twobraking device assembly and a monitoring logic system to ascertain whether one activated braking device could maintain the lift car stationary. On safety gear, Muller (2003) developed a safety device to monitor a movable element for use in lift systems where a speed determination unit, a distance determination unit, a comparator, and a triggering unit were available to monitor the key components such as machine brake, safety gear and buffers. Tim (2014) studied the deceleration of a safety gear tested in an empty lift car with known counterweight influences and found that the force of safety gear developed was independent of the weight to be decelerated or its speed. Kattainen et al. (2016) developed a programmed control system for ease of efficient maintenance work. More general research studies have also been conducted on diagnosing the operational conditions for brake and safety gear systems. Lonkwic et al. (2016a) studied the impact of variable operating conditions on the value of braking process delay for progressive gears. Wolszczak et al. (2019) studied the nonlinear mechanics of an elevator brake system subjected to uncertainties. Lonkwic et al. (2016b) conducted independent tests on the impact of progressive gears in short distance transportation devices due to geometry. Lonkwic et al. (2017) presented a new design to deal with changeable operating conditions on the deceleration of progressive safety gears.

This study aims at improving and enhancing the traditional inspection with support of real-time sensor data on the four critical parameters, taking into consideration of some critical fault symptoms and lessons learnt from preceding lift incident cases for addressing the following two practical challenges:
(1) Challenge of continually monitoring the effectiveness of brake plungers and detection of abnormalities occurring between brake linings and the brake drum, which may not be easily inspected during routine servicing except overhaul work.

(2) Challenge of stepped-up testing frequency of car safety gear on free-fall testing scenario with no test weight, aiming for causing least mechanical stress and protecting the components of the safety gear.

The following sections of this study are organised as follows. The theory and method for the prototype testers are described in Section 2; Section 3 illustrates the setup and test procedures for prototype testers; experimental results and verification on brake lining temperature, brake solenoid current, vibrational patterns of brake arms and safety gear are given in Section 4.

\section{Theory and Method}

\subsection{Braking Energy for Machine Brake}

Each brake arm is equipped with two accelerometers (attached in upper and lower of the arm), as shown in Figure 1(a) in a later section, while each accelerometer includes three axes of measurement, $x$-, $y$ - and $z$ - respectively. Due to the shape of the brake arm, the choice of placement of the upper and lower accelerometers is limited. For the analysis of the vibrational patterns, the acceleration along all three axes of the upper accelerometer, $a_{x}, a_{y}$ and $a_{z}$, has to be measured at the same time. Those of the lower accelerometer are represented by $a_{l x}, a_{l y}$ and $a_{l z}$ similarly. Owing to the orientation of placement, a DC offset exists along each axis of measurement. The adjusted acceleration values, $\operatorname{Adj}\left(a_{x}\right), \operatorname{Adj}\left(a_{y}\right)$ and $\operatorname{Adj}\left(a_{z}\right)$, are produced by subtracting the raw values from the average values, Ave $\left(a_{x}\right)$, $\operatorname{Ave}\left(a_{y}\right)$ and $A v e\left(a_{z}\right)$, when the brake is applied, according to the following Equation (1), which is generally applicable to all accelerometers. Such calibration of the average values can be arranged from time to time whenever the brake is applied to improve accuracy.

$$
\operatorname{Ave}\left(a_{x}\right)=\frac{\sum_{i=1}^{N} a_{x}(i \Delta t)}{N} ; \operatorname{Ave}\left(a_{y}\right)=\frac{\sum_{i=1}^{N} a_{y}(i \Delta t)}{N} ; \operatorname{Ave}\left(a_{z}\right)=\frac{\sum_{i=1}^{N} a_{z}(i \Delta t)}{N}
$$

where the brake is applied from $\Delta t$ to $N \Delta t$ and $\Delta t=5 \mathrm{~ms}$.

$$
\begin{aligned}
& \operatorname{Adj}\left(a_{x}\right)=a_{x}-\operatorname{Ave}\left(a_{x}\right) \\
& \operatorname{Adj}\left(a_{y}\right)=a_{y}-\operatorname{Ave}\left(a_{y}\right) \\
& \operatorname{Adj}\left(a_{z}\right)=a_{z}-\operatorname{Ave}\left(a_{z}\right)
\end{aligned}
$$

The choice of $N$ in Equation (1) is subject to on-site experience which showed that $N=50$ could be sufficient, i.e. data within a time range of 0.25 seconds before any brake movement. Later, in the results section, readers 
will see the acceleration patterns while the strength of the patterns is used to determine whether the brake operation is normal or not. To measure the strength or weakness, a new benchmarking parameter, the "braking energy", $E$ (upper accelerometer) and $E_{1}$ (lower accelerometer), of a brake event is proposed as defined in Equation (2). It was verified on site, as seen in a later section, that each brake operation could be completed within 150 milliseconds and therefore the "braking energy" of a period of 300 milliseconds is computed based on 60 data sets at a sampling rate of 200 $\mathrm{Hz}$ (i.e. a period of 5 milliseconds). In fact, a longer period of calculation does no harm provided that all useful data can be embraced because when the brake is either applied or released stably, the adjusted acceleration along all three axes is close to zero.

$$
\begin{aligned}
& E=\sum_{i=1}^{60}\left[\operatorname{Adj}\left(a_{x}(i \Delta t)\right)^{2}+\operatorname{Adj}\left(a_{y}(i \Delta t)\right)^{2}+\operatorname{Adj}\left(a_{z}(i \Delta t)\right)^{2}\right] \Delta t \\
& \text { and } \\
& E_{1}=\sum_{i=1}^{60}\left[\operatorname{Adj}\left(a_{1 x}(i \Delta t)\right)^{2}+\operatorname{Adj}\left(a_{1 y}(i \Delta t)\right)^{2}+\operatorname{Adj}\left(a_{1 z}(i \Delta t)\right)^{2}\right] \Delta t
\end{aligned}
$$

\subsection{Unloaded Testing Method for Safety Gear}

According to the mandatory code of practice on lift design in Hong Kong, for the use of progressive safety gears (lift rated speed at least $1 \mathrm{~m} / \mathrm{s}$ ), the retardation shall lie between $0.2 \mathrm{~g}$ and $1 \mathrm{~g}$ where $\mathrm{g}=9.81 \mathrm{~m} / \mathrm{s}^{2}$. The design condition is a free-falling car with rated load being stopped by the operation of the safety gears. Throughout the past decades, tests on safety gears simulated the same condition by filling up the car with rated load and then releasing the brake to let the car freely fall. Recently, in order to protect the guide rails and the safety gears, the overspeed governor has been tested separately and then the speed governor of a fully loaded down moving lift has been manually triggered under maintenance speed only by most maintenance contractors. All these tests could not truly reflect the performance of the safety gears in accordance with the code of practice because:

(1) Only a free-fall simulation could automatically trigger the overspeed governor as the tripping speed is at least $15 \%$ higher than the rated speed; normally, it is difficult to simulate this speed without allowing a free-fall condition even the car is fully loaded.

(2) The safety gear is designed to stop a freely falling lift car in the downward riding mode and hold it stationary in an emergency either due to overspeed or breaking of suspension ropes; all previous and existing testing methods could not simulate this condition because the hoisting ropes always remain intact.

The safety gear tester developed in this study aims at finding out the true retardation of a fully loaded lift car under a real free fall when the machine brake fails or all hoisting ropes are broken. That explains why an extremely high sampling rate, at least $200 \mathrm{~Hz}$, of the two car top accelerometers is necessary. This method was originally developed in Germany and used in some districts in Canada. However, it is still not popular around the world (Al-Sharif, 2002). It is because of lacking a high precision accelerometer system, which was developed by this project. The standard elevator vibration analyser (i.e. EVA-625) used by most maintenance contractors does not come with the necessary hardware to record the high retardation during the operation of the safety gear unless an additional accelerometer is purchased because a standard EVA-625 only comes with a $2 \mathrm{~g}$ accelerometer mainly for testing the riding comfort of passengers. According to Al-Sharif (2002), an empty car was tested to travel downwards at a limited speed $(1 \mathrm{~m} / \mathrm{s})$ and was stopped spontaneously by manually activating the overspeed governor inside the machine room. The retardation during the first 0.1 seconds could be used to calculate the expected retardation under full load and breaking of hoisting ropes. The method is based on three assumptions:

(1) the force of the progressive safety gear is load independent, which was supported by the findings of Tim (2014);

(2) during the 0.1 seconds interval, the effect of the counterweight, the traction sheave and the hoisting ropes can be ignored because all hoisting ropes are slack;

(3) the lift car can jump to a full stop during the 0.1 seconds interval if the testing speed is at $1 \mathrm{~m} / \mathrm{s}$ because the retardation by the safety gear on an empty car is higher than $1 \mathrm{~g}$ before it stops.

It is not easy to adjust the operating speed of the lift car to $1 \mathrm{~m} / \mathrm{s}$ on site because usually there are only two speed settings, namely the rated speed and the maintenance speed at $0.5 \mathrm{~m} / \mathrm{s}$ or below. If a maintenance speed is used, the stopping duration will be too short for the accelerometers to retrieve enough meaningful data. The prototype developed in this study could improve the safety gear testing conditions to no-load and rated speed. Data of the first 0.1 seconds after triggering of the safety gear was still manipulated. Suppose the mass of the lift car plus the compensating chains/cables underneath the car is $\mathrm{mC}$ while that of the rated load is $m_{L}$. If the retardation during the 0.1 seconds under no load and rated speed $\left(a_{N L R S}\right)$ is measured, it is possible to predict the retardation under full load governor tripped speed $\left(a_{F L G T S}\right)$ by the following Equation (3). It should be noted that retardation is positive in an upward direction in this study. 
Let $F_{S G}$ be the upward force exerted by the safety gear on the lift car Under no load rated speed tripping condition,

$F_{S G}-m_{C} g=m_{C} a_{N L R S} \Rightarrow F_{S G}=m_{C}\left(a_{N L R S}+g\right)$

Under full load governor speed tripping condition,

$F_{S G}-\left(m_{C}+m_{L}\right) g=\left(m_{C}+m_{L}\right) a_{F L G T S}$

$\Rightarrow F_{S G}=\left(m_{C}+m_{L}\right)\left(a_{F L G T S}+g\right)$

$\therefore a_{F L G T S}=\frac{m_{C} a_{N L R S}-m_{L} g}{\left(m_{C}+m_{L}\right)}$

The target is to check whether $a_{F L G T S}$ lies between $0.2 \mathrm{~g}$ and $1 \mathrm{~g}$ for ensuring normal operation of the safety gear. During the 0.1-second duration, the acceleration, which shall be regarded as retardation, of the lift car is recorded by the embedded system under a sampling rate of $200 \mathrm{~Hz}$ (the higher the better), with 20 usable data sets. The retardation is integrated to plot out the variation of speed of the lift car. Linear regression is carried out to estimate the average retardation during the 100 milliseconds duration. As a matter of fact, the duration for linear regression estimate could be as long as $v / g \times 1000$ milliseconds because the safety gear is triggered when the lift is moving down under its rated speed, $v$, which is 1.6 $\mathrm{m} / \mathrm{s}$ for our pilot lift; therefore, the maximum allowable period of linear regression should be 163 milliseconds long. Further integrating the speed variation may give a sense of approximate distance travel of the lift car during the activation period of safety gear.

\section{Experimental Investigation}

The prototype development process was conducted in three stages: Stage One for setting up of hardware and software integration, Stage Two for formulating the principle of data analysis, and Stage Three for arranging a field test at a pilot traction lift at the seven-storey EMSD Headquarters Building with a rise of around 50 metres. The technical specifications of the pilot lift are given in Table 1. Temporary measuring sensors were installed inside the machine room and on the lift car to facilitate the prototype testing, and removed after the completion of site measurement work.

Table 1. Specifications of test traction lift.

\begin{tabular}{ll}
\hline Model & Fujitec passenger lift \\
\hline Lift type & ACVVVF geared traction machine \\
Nos. of stops & $8($ i.e. G/F, M/F, 1/F to $7 / \mathrm{F})$ \\
Rated capacity & $1,600 \mathrm{~kg} / 21$ passengers \\
Counterweight & $3,100 \mathrm{~kg}$ \\
Hoisting rope weight & $0.878 \mathrm{~kg} / \mathrm{m}$ \\
Nos. of compensating chains & $2($ unknown weights $)$ \\
Rated speed of lift & $1.6 \mathrm{~m} / \mathrm{s}$ \\
Maintenance speed of lift & $0.25 \mathrm{~m} / \mathrm{s}$ \\
Tripping speed of overspeed $1.93 \mathrm{~m} / \mathrm{s}$ electrical \\
governor & $2.15 \mathrm{~m} / \mathrm{s}$ mechanical \\
Diameter of drive sheave & $850 \mathrm{~mm}$ \\
Gear ratio & $2: 79$ \\
\hline
\end{tabular}

\subsection{Hardware and Software Integration}

There are two measuring stations, one inside the lift machine room and one on the lift car top. Figure 1(a) shows the placement of sensors in the vicinity of the brake. On each brake arm, there are two accelerometers and one temperature sensor, shown in Figure 1(b). A rotary encoder, shown in Figure 1(c), is attached to one end of the axle of the drive motor so that the real-time speed and position of the lift car can be estimated. The encoder is in contact with the lift motor axle and a spring mechanism is used to secure a firm contact even under a high rotating speed. A DC current transformer is used to monitor the total DC current passing through the two brake solenoids, as shown in Figure 1(d). In addition, five relay dry contacts are provided to indicate the real-time status of a) brake operation (be it closed or opened), b) safety gear operation (be it closed or opened), c) ground floor position (for resetting the counter of the rotary encoder), d) lift car motion (be it stationary or moving), and e) direction of movement (be it upward or downward) to interrupt the computer regarding relevant events. They are all monitored by an in-machine-room embedded computer which is continuously communicating with another on-cartop embedded computer via Wi-Fi.

(a)

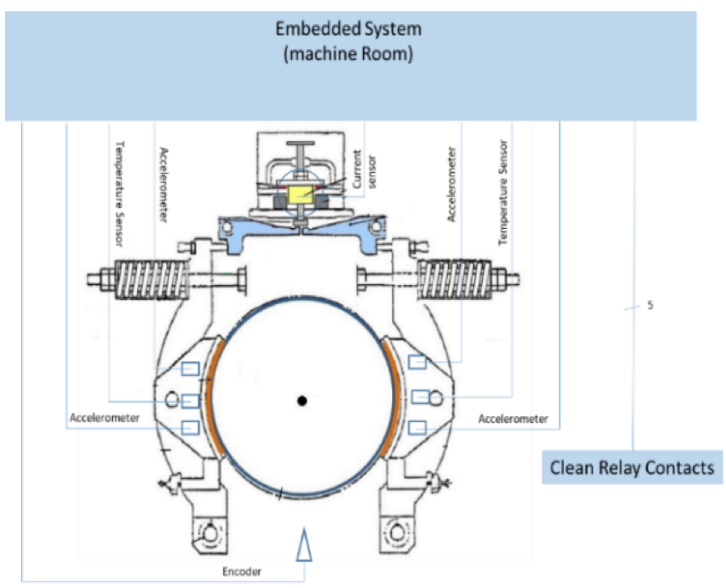

(b)

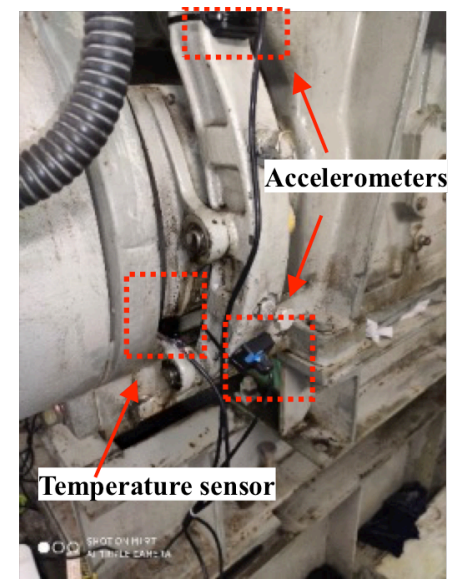


(c)

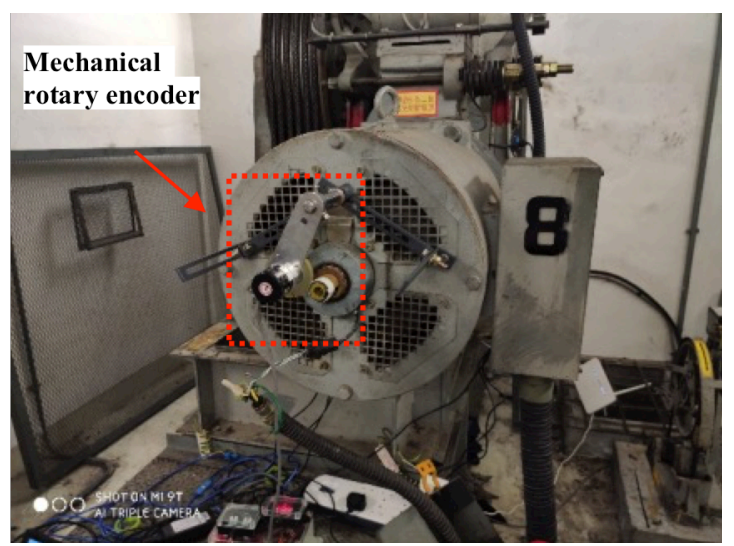

(d)

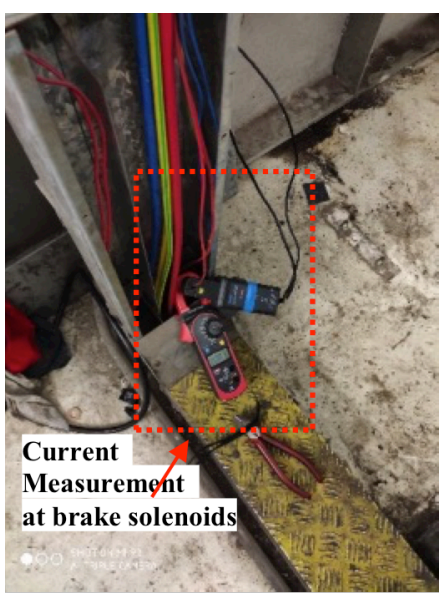

Figure 1. (a) Embedded system inside lift machine room. (b) Three sensors on right brake arm. (c) Mechanical rotary encoder. (d) Current sensor monitoring the brake solenoid current.

Figure 2(a) shows the on-car-top embedded system and three sensors while Figure 2(d) shows the real system. Two accelerometers, one on the left and one on the right of the crosshead, are shown in Figures 2(b) and 2(c). Figure 2(c) also shows an infrared device to check the operation of the mechanical linkage of the safety gear. The use of WiFi is good enough because the maximum distance between the car top and the machine room is less than $60 \mathrm{~m}$ while there is no blockage along the lift shaft between the two. Normally, Wi-Fi on $802.11 \mathrm{n}$ could have a range up to $90 \mathrm{~m}$ without blockage, which is good enough for most hoistways in Hong Kong. (a)

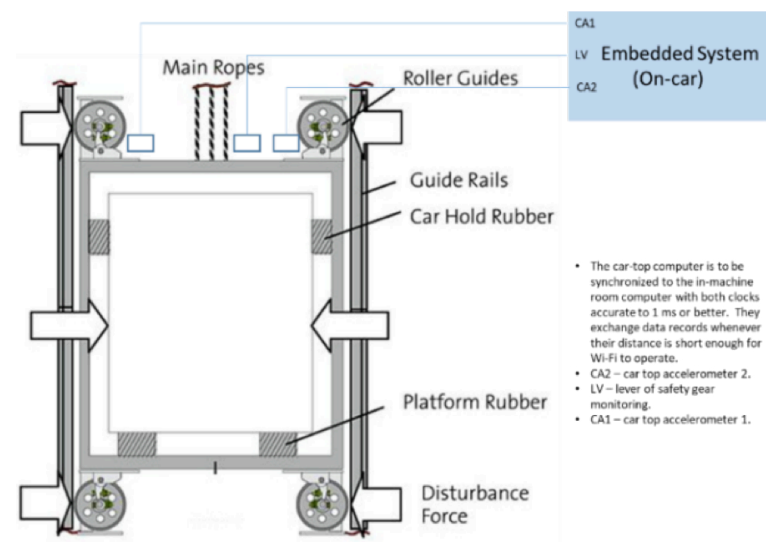

(b)

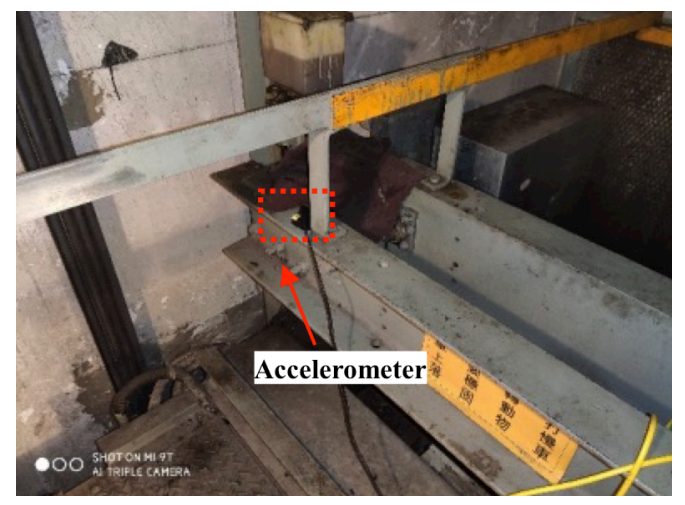

(c)

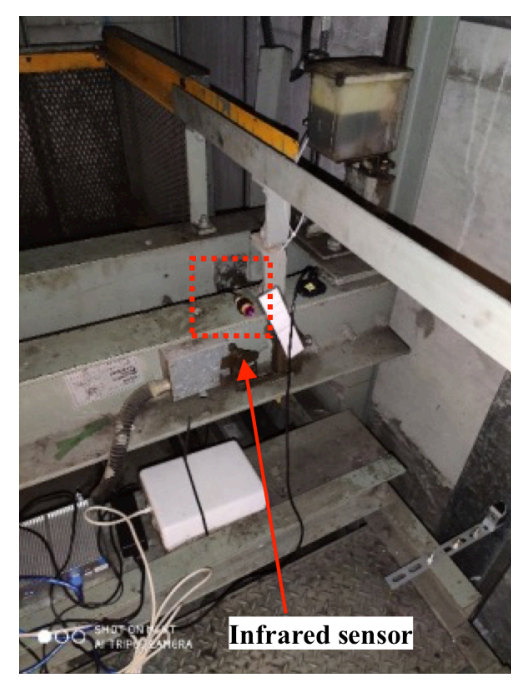


(d)

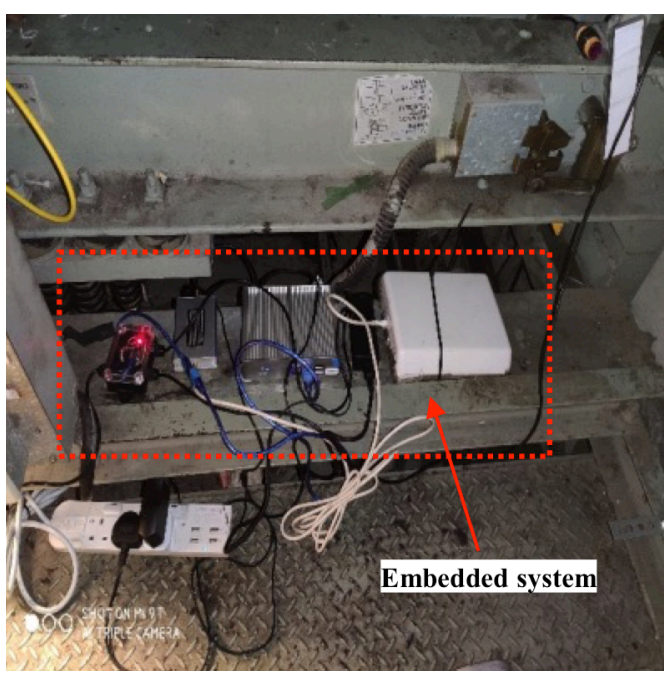

Figure 2. (a) Schematic structure of embedded system on the car top. (b) The accelerometer at the left-hand side of the car top. (c) Infrared sensor on car top. (d) Embedded system on crosshead.

\subsection{Principles of Data Analysis}

By checking the exact time when the current is injected into or removed from the solenoid and the exact time when each brake arm starts to move, it is possible to determine whether the operation of the brake solenoid and plunger is normal. By keeping track of the solenoid current, it is possible to judge whether the solenoid is normal or not. The vibrational patterns of the brake arm can reveal whether the spring or the solenoid is healthy or not. It is expected that when there is some fatigue with the spring or there is some short-circuit within the solenoid, the brake arm tends to operate a bit slow, weak or sluggish. By keeping track of the temperature of the brake lining, we can tell whether there is any partial contact between the brake lining and drum when the drum is rotating. By checking the tachometer, it is possible to confirm whether the lift car is accelerating, decelerating, moving normally, and estimate the current position of the car. By checking the decelerating patterns of the car during emergency brake or safety gear operation, it is possible to judge whether the retardation is according to the mandatory code of practice. By integrating the data from the two on-car-top accelerometers, the distance travelled by the lift car during emergency braking or safety gear operation can be estimated, though it may not be very accurate.

The sampling rate of the five relay contacts, current sensor, temperature sensors, and safety gear linkage sensor is $10 \mathrm{~Hz}$ while that of the accelerometers is $200 \mathrm{~Hz}$ (the higher the better). The rotary encoder is monitored separately. Three types of events trigger permanent data storage, namely a brake applied event, a brake released event, and the speed governor activation event. For each event, ten seconds ( -5 seconds to +5 seconds) of data centred at the event time are stored permanently for further analyses. It has been verified on site that all useful data for each event are actually within a time period of 1 second.

For the brake accelerometers, data from all three axes are adjusted and combined together to form the "braking energy" for benchmarking purposes. The acceleration when the car is stationary must be vertically equal to $g$. Therefore, the three axes of both car-top accelerometers have to be transformed to another co-ordinate system with the z-axis pointing vertically downwards. The transformation exercise is readily carried out whenever the car is stationary with $i=$ $1, \ldots, n$ number of rows, $\left(a_{x}(i \Delta t), a_{y}(i \Delta t), a_{z}(i \Delta t)\right)$, given by the following Equation (4).

$$
\left(\begin{array}{lll}
a_{x}(1) & a_{y}(1) & a_{z}(1) \\
a_{x}(2) & a_{y}(2) & a_{z}(2) \\
a_{x}(3) & a_{y}(3) & a_{z}(3) \\
a_{x}(4) & a_{y}(4) & a_{z}(4) \\
\mathrm{g} & \mathrm{g} & \mathrm{g} \\
\mathrm{g} & \mathrm{g} & \mathrm{g} \\
\mathrm{g} & \mathrm{g} & \mathrm{g} \\
a_{x}(n) & a_{y}(n) & a_{z}(n)
\end{array}\right)=\mathbf{A} \quad \times \quad \mathbf{B} \approx \mathbf{C}=\left(\begin{array}{lll}
0 & 0 & 9.81 \\
0 & 0 & 9.81 \\
0 & 0 & 9.81 \\
0 & 0 & 9.81 \\
\mathrm{~g} & \mathrm{~g} & \mathrm{~g} \\
\mathrm{~g} & \mathrm{~g} & \mathrm{~g} \\
\mathrm{~g} & \mathrm{~g} & \mathrm{~g} \\
0 & 0 & 9.81
\end{array}\right)
$$

By the standard least square approximation,

$$
\mathbf{B}=\left(\mathbf{A}^{\mathrm{T}} \mathbf{A}\right)^{-1} \mathbf{A}^{\mathrm{T}} \mathbf{C}
$$

Figure 3(a) shows the correlation between the car position and the accumulated pulse number from the rotary encoder, first in an express down trip and then a floorby-floor up trip. Figure 3(b) shows the calibration of the rotary encoder where a straight line of accumulated pulse number against the floor height was obtained, meaning that the encoder is rather accurate. Resetting the encoder to zero whenever the lift arrives on G/F can further improve accuracy, round trip by round trip, by removing accumulated errors possibly due to slippage between the hoisting ropes and the grooves of the drive sheave.

(a)

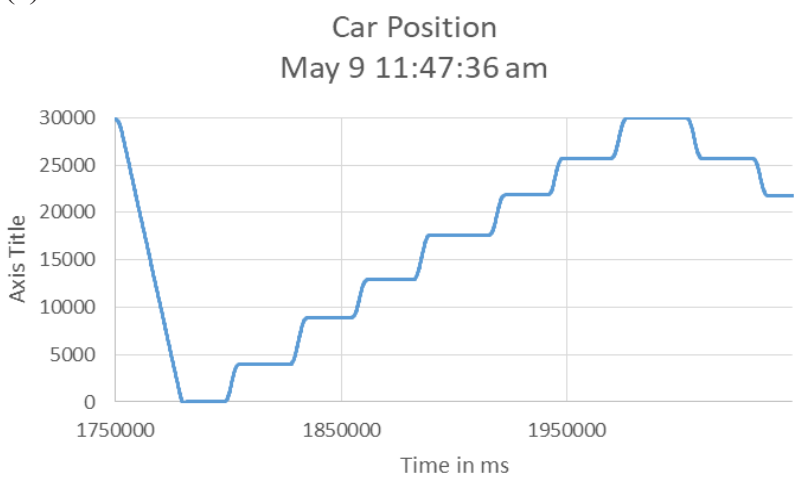


(b)

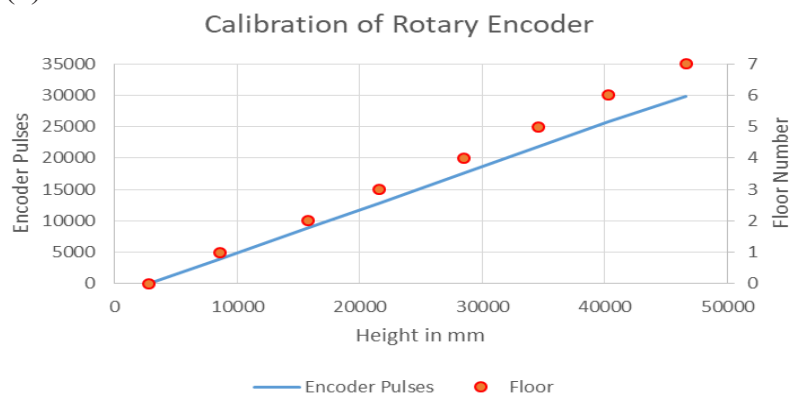

Figure 3. (a) Downward express trip and floor-by-floor tracking. (b) Linear relationship between floor height and accumulated pulses from encoder.

\subsection{Field Test at the Pilot Lift}

All tests were performed and supervised under a registered lift contractor at the (1) maintenance speed of $0.25 \mathrm{~m} / \mathrm{s}$ in full-load condition and (2) rated speed of $1.6 \mathrm{~m} /$ $\mathrm{s}$ in no-load condition at a pilot traction lift at the EMSD Headquarters Building to verify the feasibility of the prototype testers. The test procedures were as follows:

(1) Tested and verified the data-processing system of the prototype by operating the lift car without any load from $\mathrm{G} / \mathrm{F}$ to $7 / \mathrm{F}$ and from $7 / \mathrm{F}$ to $\mathrm{G} /$ $\mathrm{F}$ three times and checked the accuracy of all readings from the accelerometers, temperatures sensors, tachometer, and current sensor.

(2) Tested the lift car in no-load condition. Operated the lift car to travel down from top floor until the rated speed was reached. Manually activated the overspeed governor wheel and then the safety gears close to the top floor.

(3) Same as (2) but activated the overspeed governor close to the ground floor.

(4) Same as (2) but activated the overspeed governor on a middle floor.

(5) Fully loaded the lift car and manually activated the overspeed governor close to the ground floor at a maintenance speed.

(6) Inserted tapered feeler gauges with thicknesses of $0.25 \mathrm{~mm}$ and $0.30 \mathrm{~mm}$ in the clearance between the brake lining and brake drum to simulate the situations with protruding screws.

\section{Results and Discussion}

\subsection{Brake Lining Temperature}

Figure 4 shows the real-time temperature readings of the two brake linings. Since the brake operated normally, there was no contact between the linings and the rotating brake drum. Thus, the temperature of the brake linings was identical to the machine room ambient temperature. The precision of such measurement is not demanding because partial engagement of the machine brake based on past experience (EMSD 2018) could result in a very significant increase in temperature in terms of tens of degree Celsius.

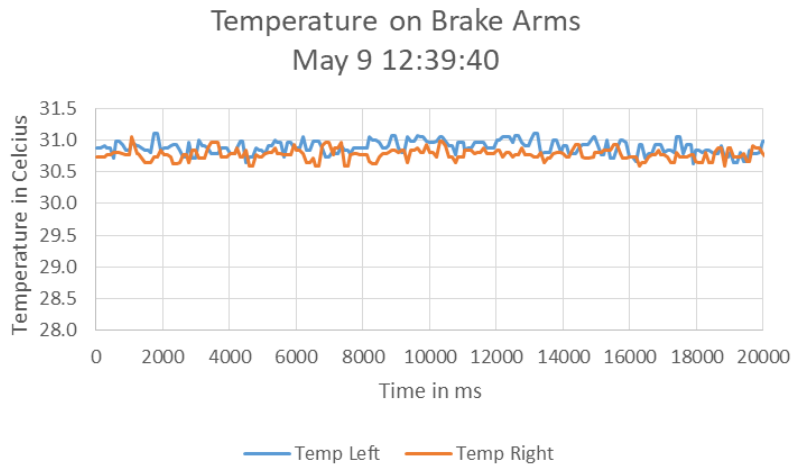

Figure 4. Typical temperature readings of the left and right brake linings.

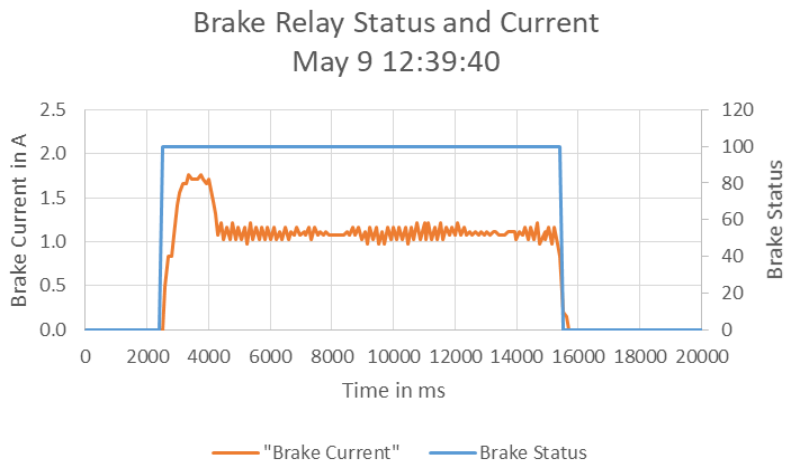

Figure 5. Brake status vs solenoid current.

\subsection{Brake Solenoid Current}

Although there were two brake solenoids, the main supply current to both solenoids was from one source and could be measured by one DC current transformer. Figure 5 shows that the brake current increased immediately after the brake released signal was received from relay 1 and reached a peak value of around 1.8 A and descended back to around $1.1 \mathrm{~A}$ after 2 seconds to keep the brake open for long.

\subsection{Vibration Patterns of Brake Arms}

This is the key element of the whole system. Figures 6(a) - 6(d) show the acceleration patterns of the upper and lower accelerometers monitoring the right brake arm under released and applied actions. These acceleration patterns are rather standard with a healthy brake as tested several times on-site. 
(a)

Right Brake Ac Released, Normal, Adjusted May 9 12:39:40

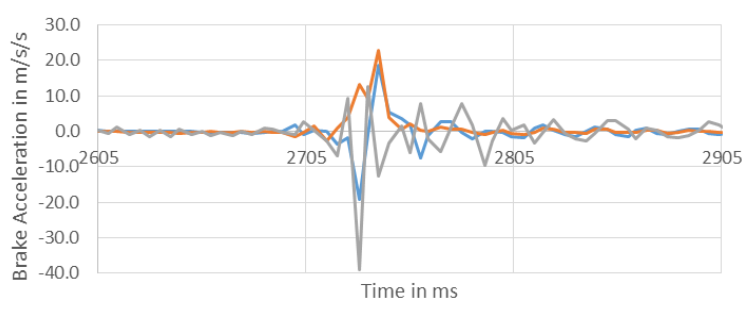

$-\mathrm{ACX}-\mathrm{ACY}-\mathrm{ACZ}$

(b)

Right Brake Ac1 Released, Normal, Adjusted May 9 12:39:40

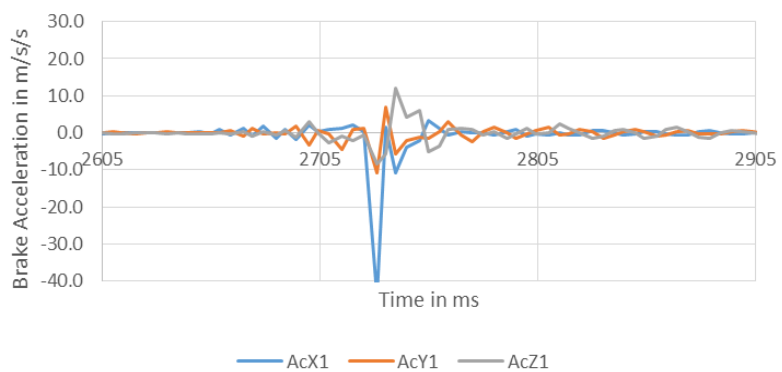

(c)

Right Brake Ac Applied - Normal, Adjusted May 9 12:39:40

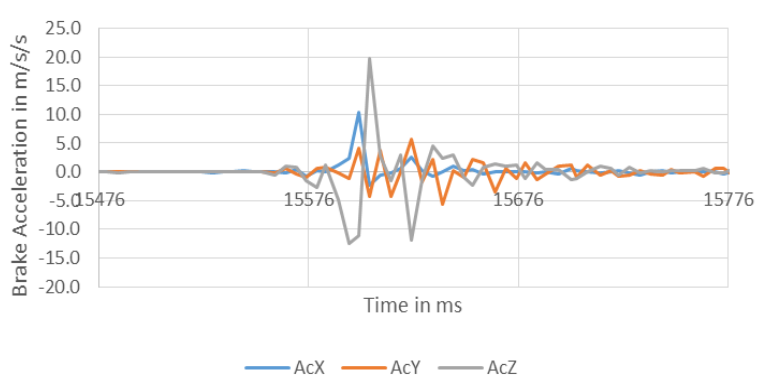

(d)

Right Brake Ac1 Applied - Normal, Adjusted May 9 12:39:40

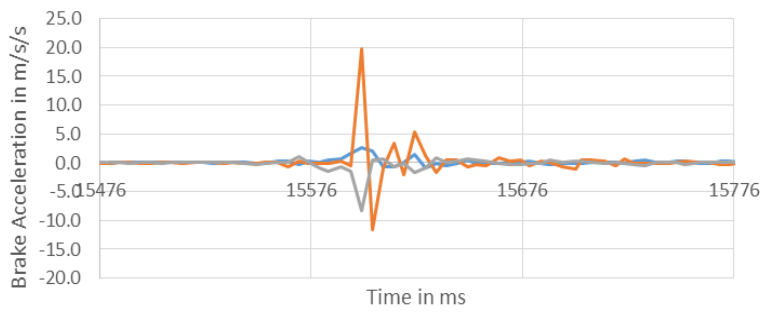

-AcX1 - $\mathrm{AcY} 1-\mathrm{AcZ1}$

Figure 6. (a) Upper accelerometer under brake released. (b) Lower accelerometer under brake released. (c) Upper accelerometer under brake applied. (d) Lower accelerometer under brake applied.
In order to test whether the tester is able to determine some abnormality with the brake operation, one incident related situation regarding the loosened screws that fixed the brake lining onto the brake arm was simulated by putting a tapered feeler gauge between the lining and the brake drum when the brake was applied. Figures 7(a) - 7(b) show the acceleration patterns when tapered feeler gauges of different thickness, $0.25 \mathrm{~mm}$ and $0.3 \mathrm{~mm}$ respectively, were inserted while the right brake was applied.

By checking the eight figures, from Figure 6(a) to Figure $7(d)$, there are the following observations.

(a)

Right Brake Ac Applied - 0.25 mm feeler, Adjusted

May 9 12:31:01

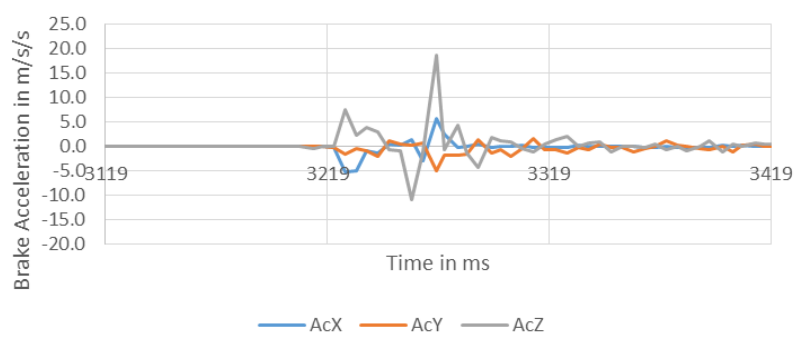

(b)

Right Brake Ac1 Applied - 0.25 mm feeler, Adjusted May 9 12:31:01

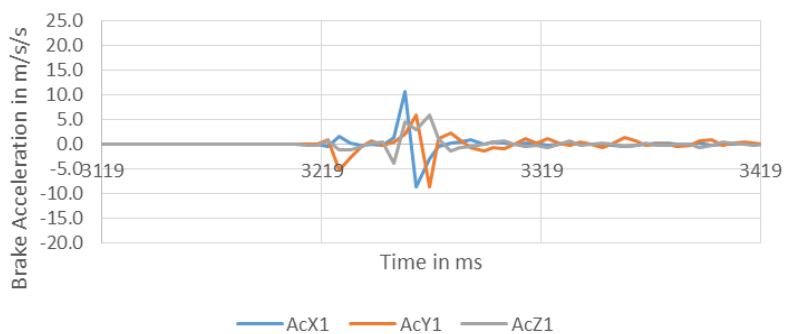

(c)

Right Brake Ac Applied - 0.3 mm feeler, Adjusted May 9 12:31:01

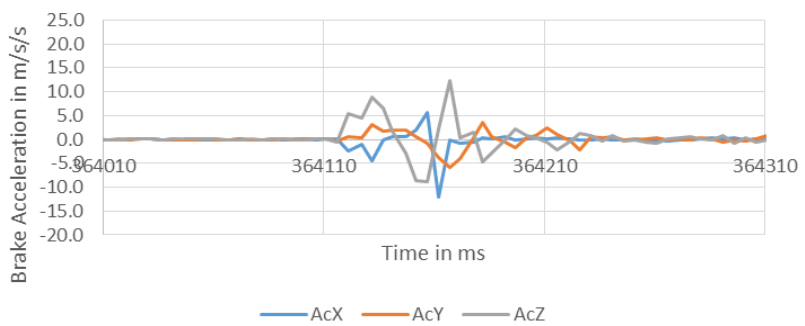


(d)

\section{Right Brake Ac1 Applied - 0.3 mm feeler, Adjusted}

May 9 12:31:01

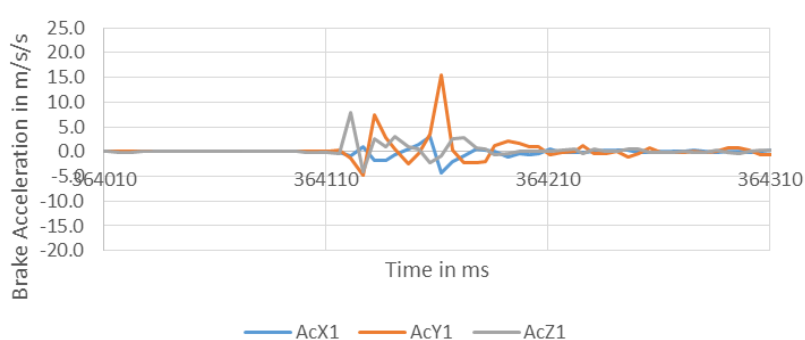

Figure 7. (a) Upper accelerometer when brake applied with $0.25 \mathrm{~mm}$ feeler. (b) Lower accelerometer when brake applied with $0.25 \mathrm{~mm}$ feeler. (c) Upper accelerometer when brake applied with $0.3 \mathrm{~mm}$ feeler. (d) Lower accelerometer when brake applied with $0.3 \mathrm{~mm}$ feeler.

(1) The acceleration pattern is stronger when the brake is released than it is applied; that makes sense because brake closing is mainly by a spring action which is a passive means while brake opening is by an electromagnetic force.

(2) When released, the brake arm movement could be completed within 60 milliseconds but within 100 milliseconds when applied, slightly longer in time; that also makes sense due to a similar reason as Item (a).

(3) The acceleration patterns of the upper accelerometer (Ac) seem to be weaker when a tapered feeler gauge is inserted between the lining and the drum.

(4) Visually, the acceleration patterns of the lower accelerometer (Ac1) seem to be more or less unchanged when a tapered feeler gauge is inserted; this also makes sense because the lower accelerometer is close to the pivot where movement is intrinsically smaller.

In order to quantitatively compare the acceleration patterns when the brake is applied, with and without a tapered feeler gauge, the "braking energy" benchmarking parameter has been suggested as detailed in Section 2.1. The result of analysis is shown in Table 2.

Table 2. "Braking Energy" of different scenarios of the applied right brake with and without tapered feeler gauge.

\begin{tabular}{|c|c|c|c|}
\hline Figure number & Feeler thickness & Accelerometer & Braking energy \\
\hline Figure 6(c) & $0 \mathrm{~mm}$ & Upper & 6.18 \\
\hline Figure 7(a) & $0.25 \mathrm{~mm}$ & Upper & 4.31 \\
\hline Figure 7(c) & $0.3 \mathrm{~mm}$ & Upper & 4.31 \\
\hline Figure 6(d) & $0 \mathrm{~mm}$ & Lower & 3.43 \\
\hline Figure 7(b) & $0.25 \mathrm{~mm}$ & Lower & 2.43 \\
\hline Figure 7(d) & $0.3 \mathrm{~mm}$ & Lower & 2.75 \\
\hline
\end{tabular}

Table 2 clearly shows that the "energy" of a healthy applied brake is higher than that of a brake with a tapered feeler gauge inserted. From an absolute value point of view, the differences with the upper accelerometer are larger than those with the lower accelerometer. Readers may also want to know, for reference, that the "energy" of Figure 6(a) is 22.61 for the upper accelerometer and 16.03 for the lower accelerometer of Figure 6(c) when the brake is released. The "energy" when the brake is released is much higher than that when applied, as explained above due to the electromagnetic force. That explains observations (a), (c) and (d). This "braking energy" benchmarking parameter seems to be a good parameter to judge whether the brake operates healthily or not.

\subsection{Vibration Patterns of the Safety Gear}

Two tests were carried out on-site without load. Under a rated speed downward journey, the overspeed governor was manually triggered. Figure Set 8 shows the results of the first test while Figure Set 9 shows those of the second test.

(a)

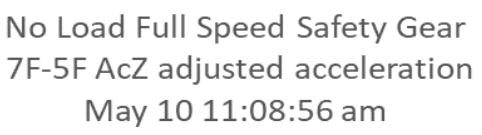

No Load Full Speed Safety Gear 7F-5F AcZ adjusted acceleration May 10 11:08:56 am

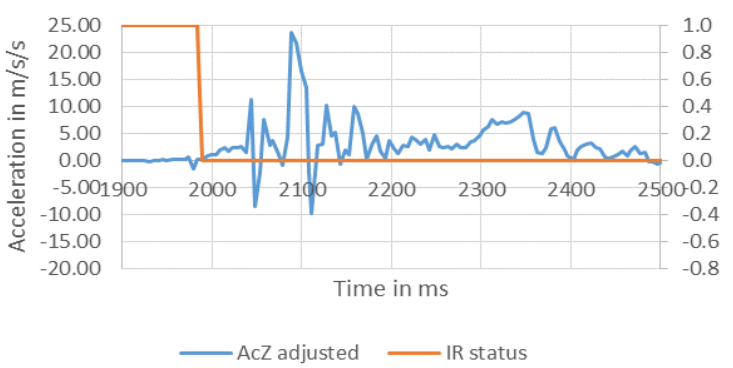

(b)

No Load Full Speed Safety Gear 7F-5F AcZ1 adjusted acceleration May 10 11:08:56 am

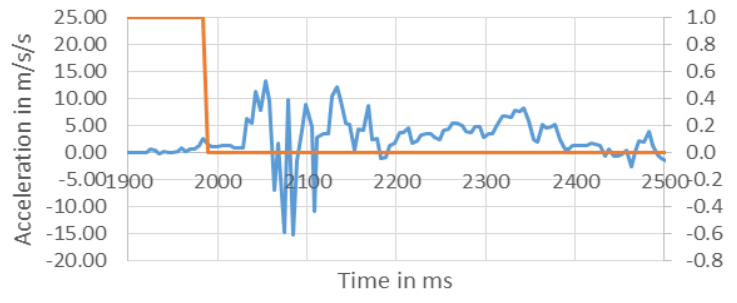

—AcZ1 adjusted —IR Status 
(c)

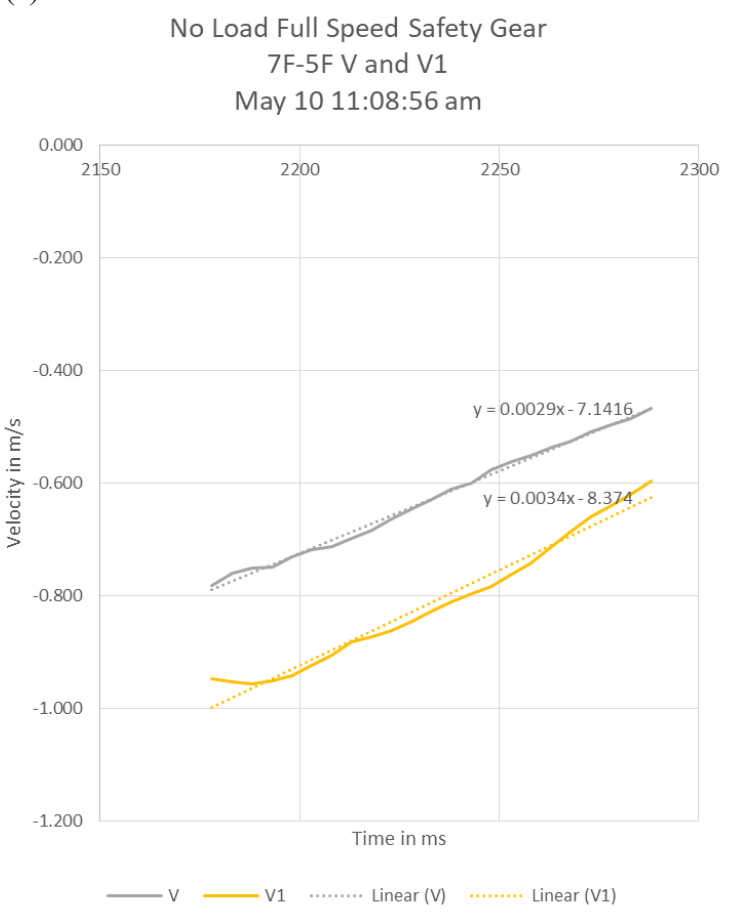

Figure 8. (a) Raw data of AcZ (no load full speed safety gear operation - Test 1). (b) Raw data of AcZ1 (no load full speed safety gear operation - Test 1). (c) Processed data of AcZ and AcZ1 (no load full speed safety gear operation Test 1).

Figures 8(c) and 9(c) depict the result of integration of the acceleration patterns, i.e. the velocity curves, one for the right accelerometer and one for the left accelerometer where Figures 8(a), 8(b), 9(a) and 9(c) show the raw data; IR stands for the infrared detector that senses the operation of the safety gear link. Linear regression produces a least squared fitted straight line for each velocity curve. The constant multiplied by $\mathrm{x}$ gives the average retardation in $\mathrm{m} /$ $\mathrm{s} / \mathrm{ms}$ which should be multiplied by 1,000 to give a unit of $\mathrm{m} / \mathrm{s} / \mathrm{s}$. It should be noted that the initial speed to kick-start the integration is irrelevant. What is critical is the average retardation during the 100 milliseconds interval when the car is decelerating.

(a)

No Load Full Speed Safety Gear $3 F-1 F$ AcZ adjusted acceleration May 10 11:17:47 am

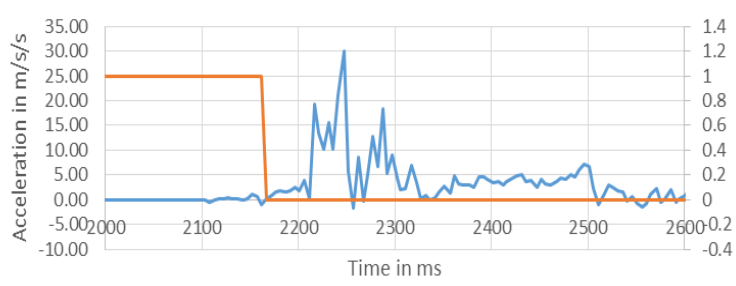

— AcZ adjusted —IR status (b)

$$
\begin{aligned}
& \text { No Load Full Speed Safety Gear } \\
& \text { 3F - 1F AcZ1 adjusted acceleration } \\
& \text { May } 10 \text { 11:17:47 am }
\end{aligned}
$$

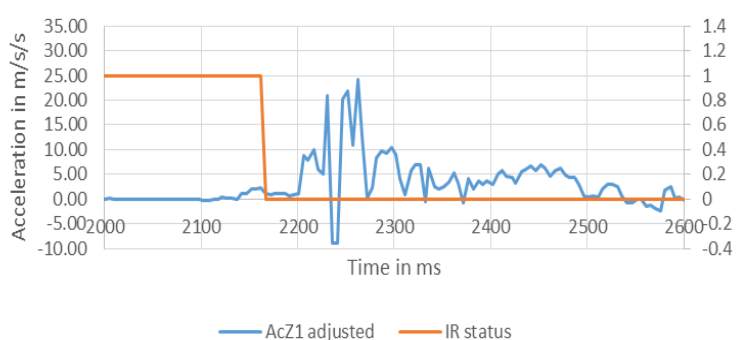

(c)

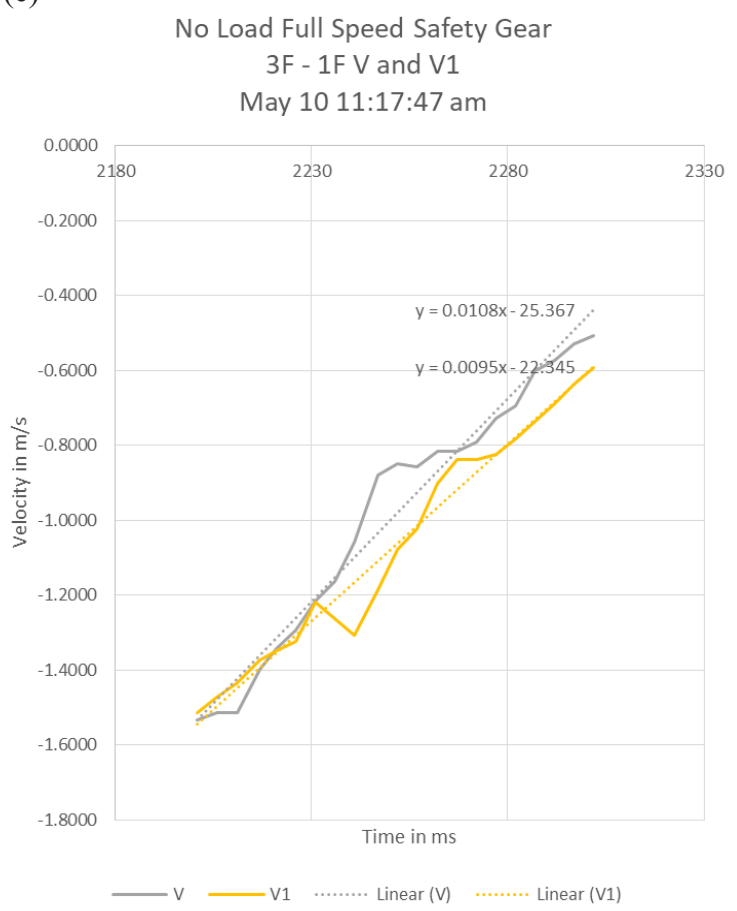

Figure 9. (a) Raw data of AcZ (no load full speed safety gear operation - Test 2). (b) Raw data of AcZ1 (no load full speed safety gear operation - Test 2). (c) Processed data of AcZ and AcZ1 (no load full speed safety gear operation Test 2).

For demonstrating that the method works, Figure Set 10 shows the result when the lift car was fully loaded and under maintenance speed. Such retardation patterns were rather similar to those of a real full-loaded free-fallingcar safety gear test. This is for comparison with the results of Figure Sets 8 and 9. But the useful deceleration time of around 25 milliseconds $(0.25 \mathrm{~m} / \mathrm{s}$ divided by g) was too short for the data to be meaningful. For real practice in future, no-load rated speed manual governor activation tests may be conducted more frequently, say half-yearly, to closely monitor the latest operating condition of the safety gear, on top of the existing full-loaded tests. 
(a)

Full Load Low Speed Safety Gear $1 F$ - GF AcZ adjusted acceleration May 10 10:54:40 am

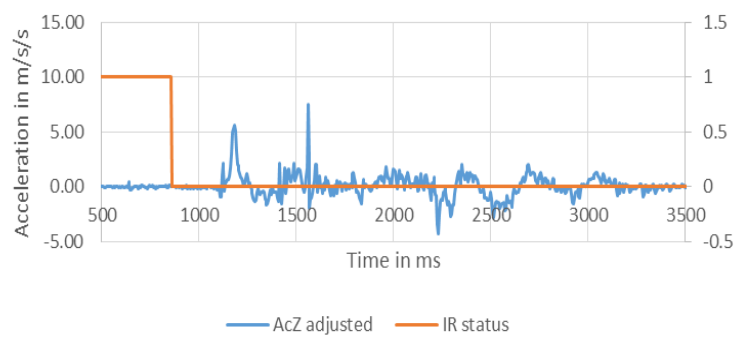

(b)

Full Load Low Speed Safety Gear 1F - GF AcZ1 adjusted acceleration May 10 10:54:40 am

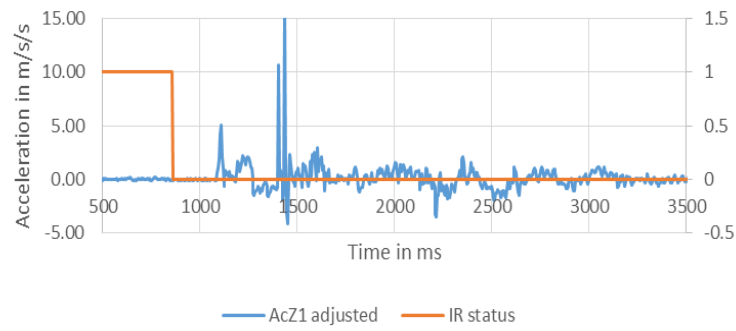

(c)

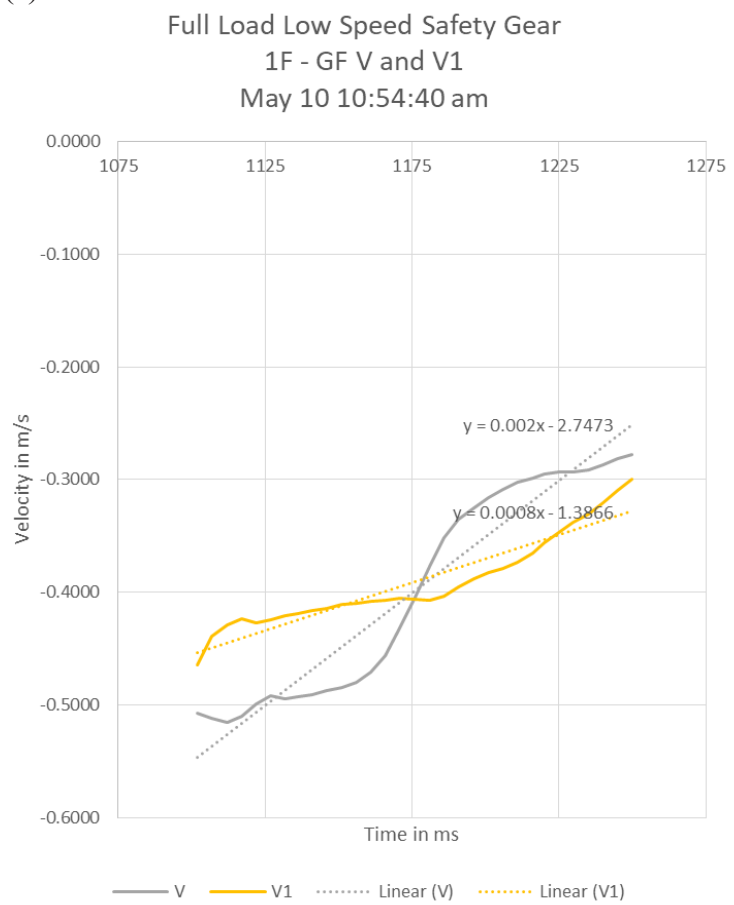

Figure 10. (a) Raw data of AcZ (full load low speed safety gear operation). (b) Raw data of AcZ1 (full load low speed safety gear operation). (c) Processed data of AcZ and AcZ1 (full load low speed safety gear operation).
By comparing the three figure sets, 8-10, there are two observations as follows:

(1) Under a no-load condition, substantial retardation started within 50 milliseconds after the safety gear mechanism was activated; but under a full load condition, substantial retardation started almost 300 milliseconds after the safety gear mechanism had been activated; that means when the car is fully loaded and at a maintenance speed, the assumption that no effect on the car from the hoisting ropes is not valid anymore.

(2) The retardation was larger on a lower floor; that could be explained by the fact that although the weight of the lift car remained unchanged, the weight of the compensating chains and travelling cables below the car varied.

Table 3 shows the average retardation of the three figure sets.

Table 3. Summary of retardation under different tests.

\begin{tabular}{|c|c|c|c|c|}
\hline Scenario & $\begin{array}{c}\text { Testing Condition } \\
(\text { Floor on which safety gear } \\
\text { was manually triggered) }\end{array}$ & $\begin{array}{c}\text { Right side } \\
\text { of lift car } \\
\left(\mathrm{m} / \mathrm{s}^{2}\right)\end{array}$ & $\begin{array}{c}\text { Left side } \\
\text { of lift car } \\
\left(\mathrm{m} / \mathrm{s}^{2}\right)\end{array}$ & $\begin{array}{c}\text { Average } \\
\left(\mathrm{m} / \mathrm{s}^{2}\right)\end{array}$ \\
\hline 1 & No-load rated speed $(5 / \mathrm{F})$ & 2.9 & 3.4 & 3.2 \\
\hline 2 & No-load rated speed (1/F) & 10.8 & 9.5 & 10.2 \\
\hline 3 & $\begin{array}{c}\text { Full-load maintenance } \\
\text { speed (G/F) }\end{array}$ & 2.0 & 0.8 & 1.4 \\
\hline
\end{tabular}

Since the pilot lift was installed decades ago, the lift maintenance contractor could only advise that the total mass of counterweight be equal to $3,100 \mathrm{~kg}$, and rated load $\left(m_{L}\right) 1,600 \mathrm{~kg}$. The density of the compensating chains was unknown. The mass of the lift car could be reasonably assumed and calculated as around $50 \%$ of the vacant lift car plus half of the rated load (i.e. $m_{C}+0.5 m_{L}=3,100$ ), implying $m_{C}=2,300 \mathrm{~kg}$.

Without knowing the exact mass of the compensating chains underneath the lift car, only Scenario 2 stated in Table 3 could be used to determine $a_{F L G T S}$ because they could be assumed negligible on $1 / \mathrm{F}$. And it was estimated to be equal to $1.99 \mathrm{~m} / \mathrm{s}^{2}=0.2 \mathrm{~g}$, marginally meeting the requirement of the current code of practice. As a matter of fact, this figure was rather close to that obtained in Scenario 3 when the car was fully loaded. The relatively small experimental error between the real $1.4 \mathrm{~m} / \mathrm{s}^{2}$ and the estimated $1.99 \mathrm{~m} / \mathrm{s}^{2}$ could demonstrate the validity of this method. It is reasonable that the fully loaded maintenance speed safety gear test gave a different retardation because the effect of the hoisting ropes could not be ignored anymore owing to the very low maintenance speed though the effect from the compensating chains could still be negligible as the tripping was done on $\mathrm{G} / \mathrm{F}$. 


\section{Conclusions}

This paper presents the design and experimental findings for the proof-of-concept prototype machine brake and car safety gear testers with the aid of sensors for monitoring the real-time variations of brake lining temperature, brake solenoid current, vibrational patterns of brake arms and safety gear to detect symptoms of abnormalities. The prototype serves as a trial for demonstrating an alternative faster means to monitor and test emergency safety devices, supplementing the current trade practice on overhaul maintenance works twice a year as per manufacturers' guidelines.

The machine brake tester is capable of detecting abnormality in the braking system by monitoring the temperature of the brake linings, the current through the brake solenoids, the action of the brake arms after the current is energised and de-energised, and most important the acceleration patterns of the brake arms which can give hints on the health of the brake plunger and the spring. The proposed "braking energy" with other raw data could give a simple benchmarking parameter for maintenance staff to quickly find out whether there is any fault with the braking system because it is unreasonable to expect maintenance technicians manually and visually do further analyses of the acceleration patterns on site.

For improving the current traditional testing method on the safety gears with less mechanical pressure on both the jaws of the gears and the guide rails, the method of no-load rated speed manual triggering of the overspeed governor could be considered, so that no test weight and no adjustment of the rated speed are needed to facilitate more safety gear tests to verify its functionality on a more frequent basis.

The prototype has shown a good application potential as a quick monitoring alternative to existing and new traction lift systems in order to further enhance the efficiency of safety inspection for continual health check purposes. However, more on-site tests are certainly required to verify the prototype system is accurate enough to be relied on. Further improvements on the prototype such as an integrated assembly of sensors, the increase in the sampling frequency of the six accelerometers, and an automatic generation of processed data are certainly necessary.

\section{Acknowledgements}

This work was financially supported by the Electrical \& Mechanical Services Department, the HKSAR Government, People's Republic of China.

\section{Notes on Contributors}

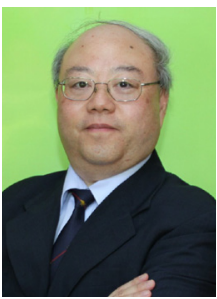

Ir Dr Albert T P So received his undergraduate and postgraduate degrees, all in electrical and electronic engineering from The University of Hong Kong. $\mathrm{He}$ is an Executive Board member and Scientific Advisor to the International Association of Elevator Engineers and the founding academic secretary of its Hong Kong Branch. He is also a Technical Advisor to Elevator World, a top magazine for the industry. Over the past two decades, he has been actively involved in research, code making and accident investigation on lift systems. And he proposed the lift and escalator objects in BACnet, which was approved in 2016.

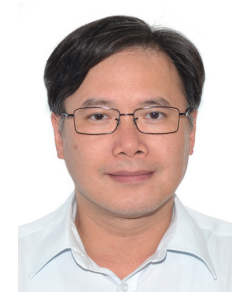

Dr K H Lam received his bachelor's degree in Electrical and Electronic Engineering from The University of Hong Kong in 1994. He worked in the building services industry after graduation and returned to his alma mater for joining the HKU Photovoltaic research team in 1998. His research focus is on photovoltaic systems integration. In 2007, he received his Ph.D. in Architecture from The University of Hong Kong and started to work as a Senior Manager in a solar energy company. He was elected Chairman (2008-2009) of the Hong Kong Photovoltaic Consortium. In May 2014, he was appointed as Lecturer by the Department of Electrical \& Electronic Engineering at The University of Hong Kong; and then Honorary Assistant Professor by the same department in February 2016. He is a Chartered Electrical Engineer registered at the Engineering Council, UK, and a Registered Energy Assessor at the HKSAR Government.

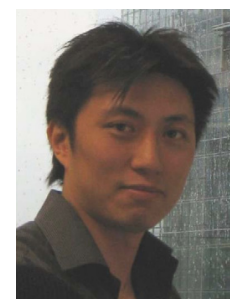

Mr Andy C T Kong received his M.Sc. in Electrical and Electronic Engineering from The University of Hong Kong (HKU) and B.A.Sc. in Electrical and Computer Engineering, Commerce Minor from The University of British Columbia, Vancouver, Canada. He is studying for a Ph.D. at HKU and has been working in different industries including embedded system, FPGA/ VHDL design, security system design, Wi-Fi router design, air pollution detection machinery, and Big LED screen. In 2017, he was one of the TEDxHK speakers about "Maker Mindset". 


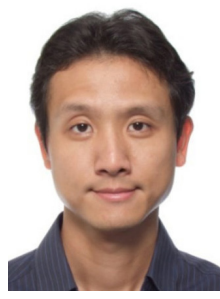

Ir Dr Jeff $\mathbf{H}$ Tse is a Chartered Engineer serving as a senior engineer at the Electrical and Mechanical Services Department of the HKSAR Government. He received his doctoral degree in Mechanical Engineering from The Hong Kong Polytechnic University. His main job duty is to explore innovative technologies applying to asset management of various public electrical and mechanical installations.

\section{References}

[1] Al-Sharif L (2002). Lift safety gear testing without weights: a critique and overview. Elevator Technology 12, Proceedings of Elevcon 2002, Milan: IAEE, pp. 10-19.

[2] EMSD (2013). Technical Investigation Report on Lift Incident at 478 - 480 King's Road, North Point, Hong Kong. Hong Kong: EMSD.

[3] EMSD (2018). Technical Investigation Report on Lift Incident at Paris Court, Sheung Shui Town Centre, New Territories. Hong Kong: EMSD.

[4] EMSD (2019). Code of Practice on the Design and Construction of Lifts and Escalators.

[5] Emy K, Lindegger U and Eckenstein R (2009). Brake Device for an Elevator with Monitoring Capabilities, US7909145B2.

[6] Fischer D (2008). Multiple Brake Devices for Elevator with Monitoring, US8602170B2.

[7] Hubbard J, Servia-Reymundo A and Mann M (2002). Detecting Elevator Brake and other Dragging by Monitoring Motor Current, US7350883B2.

[8] Kattainen A and Hovi A (2016). Arrangement and a Method for testing Elevator Safety Gear, US10399818B2.

[9] Lamb M and Martin M (1993). Apparatus for Monitoring Elevator Brakes, US5419415A.

[10] Lonkwic P and Syta A (2016a). Nonlinear analysis of braking delay dynamics for the progressive gears in variable operating conditions. J. Vibroengineering, 18(7), pp. 4401-4408.

[11] Lonkwic P, Szydlo K and Molski S (2016b). The impact of progressive gear geometry on the braking distance length under changeable operating conditions. Research J. Adv. Science and Technology, 10(29), pp. 161-167.

[12] Lonkwic P, Lygas K, Wolszczak P, Molski S and Litak G (2017). Braking deceleration variability of progressive safety gears using statistical and wavelet analyses. Measurement, 110, pp. 90-97.

[13] Mueller W (2003). Safety Device for Monitoring a Movable Element, US7014014B2.
[14] Peng Q, Li Z, Yuan H, Huang G, Li S and Sun X (2018). A Model-based Unloaded Test Method for Analysis of Braking Capacity of Elevator Brake. Advances in Materials Science and Engineering, 2018, Article ID 8047490.

[15] Tim E. (2014). Risk Potential of Safety Gears Inspections with Test Weights Show a Lack of Clearance. Elevator Technology 20, Proceedings of Elevcon 2014, Paris: IAEE, pp. 247-255.

[16] Wolszczak P, Lonkwic P, Cunha A, Litak G. and Molski S. (2019). Robust optimization and uncertainty quantification in the nonlinear mechanics of an elevator brake system. Meccanica, 54, pp. 1057-1069. 